\title{
A prospective study assessing patient satisfaction at a large tertiary gynecologic oncology/dysplasia unit
}

This article was published in the following Dove Press journal:

Patient Related Outcome Measures

7 October 2010

Number of times this article has been viewed

\author{
Selvan Pather' \\ Davina Tai ${ }^{2}$ \\ Shannon Philp' \\ Kathryn Nattress' \\ Jonathan Carter' \\ Christopher Dalrymple' \\ Ken Atkinson' \\ 'The Sydney Gynaecologic Oncology \\ Group, Sydney Cancer Centre, \\ Royal Prince Alfred Hospital, Sydney, \\ Australia; ${ }^{2}$ Department of Obstetrics \\ and Gynaecology, Royal Prince Alfred \\ Hospital, University of Sydney, Sydney, \\ Australia
}

Background: Patient satisfaction is an important quality assurance measure in the delivery of health care. We conducted a prospective study to assess patient satisfaction at a large tertiary oncology/dysplasia unit.

Aims: To assess current patient satisfaction at a large tertiary oncology/dysplasia unit and identify potential areas for improvement.

Methods: This was a prospective study of patients attending a tertiary oncology/dysplasia unit. Patients were invited to participate and, if they agreed, were given a validated questionnaire to complete at the end of their consultation. Descriptive statistics were then used to analyze the data and identify potential areas of improvement.

Results: One hundred eighty-seven patients were recruited, and $96 \%$ of patients were satisfied with the overall level of care received. Significant positive features of the service included helpfulness of the staff, cleanliness of the facility, and measures implemented to respect patient privacy. Lack of patient parking, waiting times in the clinic, difficulties in contacting the service, and locating the building were identified as areas for improvement.

Conclusion: Patients attending our facility were largely satisfied with the overall level of care received. Nonclinical factors including parking, waiting times, and access to the service were identified as areas for improvement.

Keywords: oncology, dysplasia, outpatient, satisfaction

\section{Introduction}

Patients' satisfaction with health care can broadly be defined as a measure of how patients' individual health care experience matches their prior expectations. This is a key end point of health care, important both in daily clinical practice and in the assessment of health treatment and services. ${ }^{1}$ There is emerging evidence that patients' compliance with cancer treatment and patients' adherence to treatment are significantly improved if patients are satisfied with the service provided. ${ }^{2,3}$ The gynecologic oncology service at the Sydney Cancer Center provides outpatient gynecologic oncology services, colposcopy services, preadmission services, and inpatient gynecologic oncology services. We had received previous informal feedback from patients, which suggested that although they were satisfied with most aspects of clinical care, nonclinical aspects of care including booking of appointments and travel to our center significantly impacted on their care. The aim of this study was to carry out a prospective assessment of outpatient satisfaction with all aspects of our service and identify potential areas for improvement.
Correspondence: Selvan Pather Level 6 Gloucester House, Royal Prince Alfred Hospital, Missenden Rd, Camperdown, 2050, Sydney, Australia Tel +61295156111

Fax +61295158434

Email spather@med.usyd.edu.au 


\section{Material and methods}

All patients presenting to the oncology/dysplasia unit at the Sydney Cancer Center were eligible for inclusion in the study. Patients who did not have English as a first language were offered an interpreter if they chose to take part in the study. The Human Ethics Committee of the Sydney South West Area Health Service approved the study.

\section{Methods}

Patients were recruited and enrolled into the study by the administration officer who is the first point of contact at the clinic. The clinical staff at the clinic did not carry out recruitment to ensure that patients who may be critical of the service were not excluded due to bias from clinicians. An information leaflet was initially presented to patients, and if they chose to take part, informed consent was obtained, and the patient was given a questionnaire to complete at the end of the consultation. The questionnaire consisted of basic demographic data followed by specific questions evaluating all aspects of outpatient care. The questions consisted of those aspects of the European Organization for Research and Treatment of Cancer in-patient satisfaction (EORTC IN-PATSAT32) ${ }^{4}$ which would be pertinent to outpatient care, as well as additional questions on the ease of making appointments, clinic accessibility, waiting times, and parking. The following scale - strongly satisfied; satisfied; neither satisfied nor dissatisfied; dissatisfied; strongly dissatisfied - was used to score patient satisfaction, and the data were analyzed as per the previously published EORTC IN-PATSAT32 study. ${ }^{4}$ The questionnaire also contained questions regarding the patient's education, family circumstances, and past critical events to assess the impact of these on patient satisfaction. Patients also gave consent for collection of specific clinical information from their medical records for further evaluation. Patients were also asked to identify the best and worst aspects of their treatment experience. This was voluntary and not a mandatory field. The study was carried out over 2 years, and patients were approached randomly over this period. This was done to account for biases resulting from short-term staff, seasonal effects on transport and parking, building works, and clinic closures due to holidays.

\section{Statistics}

All data were entered into a database and analyzed using $\mathrm{JMP}^{\circledR}$ data analytic software (SAS Institute Inc, Cary, NC).

\section{Results}

A total of 187 patients were recruited to the study conducted between September 21, 2006, and March 25, 2008. The patients' demographic data are outlined in Table 1. Approximately $96 \%$ of all patients in the survey were satisfied with the overall level of care received and would recommend the service to friends and family. The best aspects of patient care are outlined in Table 2. The worst aspects of the service included poor access to parking, difficulty in telephonically contacting the clinic, accessibility to the clinic, and waiting time in the clinic before consulting the doctor (Table 3). There were insufficient patients with an overall negative experience to allow correlation with day of the week, attending consultant, new or follow-up patient, and whether a procedure was performed at the visit. The best aspects of patient care included the courteous nature of the doctors, good communication from all staff, and receiving good news. The worst aspects of care included anxiety, long waiting time, lack of access to the clinic, and poor access to parking.

\section{Discussion}

This study demonstrates that patients were satisfied with the level of care provided. The willingness of patients at an outpatient clinical facility to recommend the service to friends and family is the single most important aspect of outpatient satisfaction surveys. ${ }^{5}$ Approximately $95 \%$ of our patients would recommend this service to others. Anxiety and time spent on waiting for a consultation were the two significant clinical factors identified in study. High levels of anxiety have been noted in patients awaiting colposcopic

Table I Patients' demographic data $(\mathrm{N}=187)$

\begin{tabular}{ll}
\hline Mean age $(y)$ & 31 (I9-32) \\
Mean parity & I (I-4) \\
Patient status & 60 \\
New & 124 \\
Follow-up & 3 \\
Unknown & \\
Level of attending doctor & 70 \\
Fellow & 54 \\
Consultant & 29 \\
Registrar & 30 \\
Medical officer & 4 \\
Unknown & \\
Diagnosis & 15 \\
Cancer & 92 \\
Dysplasia & 74 \\
Others & 6 \\
Unknown & \\
\hline
\end{tabular}


Table 2 The best aspects of care received $(\mathrm{N}=187)$

\begin{tabular}{llll}
\hline & $\begin{array}{l}\text { Strongly } \\
\text { satisfied or } \\
\text { satisfied (\%) }\end{array}$ & $\begin{array}{l}\text { Strongly } \\
\text { dissatisfied or } \\
\text { dissatisfied (\%) }\end{array}$ & $\begin{array}{l}\text { Neutral } \\
\text { (\%) }\end{array}$ \\
\hline $\begin{array}{l}\text { Quality of care } \\
\text { Recommend to friends }\end{array}$ & 96 & 1 & 3 \\
$\begin{array}{l}\text { Helpfulness of the } \\
\text { nurses }\end{array}$ & 94 & 0 & 5 \\
$\begin{array}{l}\text { Cleanliness } \\
\text { Respect for privacy }\end{array}$ & 94 & 0 & 6 \\
Time spent with doctor & 93 & 0 & 6 \\
\hline
\end{tabular}

examination. ${ }^{6,7}$ Methods which were utilized during the study period to reduce anxiety included a television in the waiting room, informational material and commercial magazines, access to a free beverage service, and reassurance and counseling by a nurse before, during, and after a consultation or colposcopic examination. In addition, all patients have access to video colposcopy, a practice which has been shown to reduce the incidence of anxiety in patients attending colposcopy for the first time. ${ }^{8}$ Also, the use of music during colposcopy has been employed to further assist with the reduction of anxiety. ${ }^{9}$

Long waiting times at outpatient clinics have been noted in many previous Australian Studies looking at patient satisfaction with outpatient ambulatory services. Oncology/dysplasia clinics have to balance the ability to see new patients within a short time and see the large number of follow-up patients in a timely fashion. This is complicated by the high default rates in colposcopy clinics, up to $21 \%$ in a large prospective randomized study..$^{10}$ Specialists at an oncology/dysplasia clinic often have to add extra patients with proven malignancy to the clinic lists at very short notice. Therefore, there is a system of overbooking clinics in anticipation of a default rate, and this leads to a variable ability to see patients in a timely fashion. The incorporation of a method of reminding patients telephonically of their appointment the day before their scheduled clinic appointment ${ }^{11}$ and reserving clinic appointments for urgent appointments has been implemented since this study, and this is likely to improve waiting times in the future.

Table 3 The worst aspects of care received $(\mathrm{N}=187)$

\begin{tabular}{llll}
\hline & Satisfied (\%) & Dissatisfied (\%) & Neutral (\%) \\
\hline Parking & 21 & 28 & 51 \\
Waiting room time & 66 & 16 & 28 \\
Telephone access & 72 & 11 & 27 \\
Accessibility & 79 & 4 & 17 \\
\hline
\end{tabular}

Nonclinical factors including parking, ease of making appointments, and clinic accessibility were the major factors influencing patient perception of clinical care. Previous similar clinical studies have confirmed influence of these factors on the perception of clinical care. ${ }^{12-14}$ Parking difficulties also affect waiting times as they result in patients arriving in groups rather than at a steady rate. ${ }^{15}$ Major renovations during the period of this study and the building of an adjacent perioperative unit significantly reduced accessibility to the clinic with a clear lack of directions to the clinic. Patients are now informed telephonically of available parking at booking and provided with references to parking related websites.

Our study identified clinical and nonclinical areas, which may be improved to enhance patient satisfaction. Significant changes have been made, and we plan to carry out a follow-up study to check on the efficacy of these interventions in improving patient satisfaction with our service.

\section{Disclosure}

The authors report no conflicts of interest in this work.

\section{References}

1. Pascoe GC. Patient satisfaction in primary health care: a literature review and analysis. Eval Program Plann. 1983;6(3-4):185-210.

2. Borras JM, Sanchez-Hernandez A, Navarro M, et al. Compliance, satisfaction, and quality of life of patients with colorectal cancer receiving home chemotherapy or outpatient treatment: a randomised controlled trial. BMJ. 2001;322(7290):826.

3. Guldvog B. Can patient satisfaction improve health among patients with angina pectoris? Int J Qual Health Care. 1999;11(3):233-240.

4. EuBrédart A, Bottomley A, Blazeby JM, et al. An international prospective study of the EORTC cancer in-patient satisfaction with care measure (EORTC IN-PATSAT32). Eur J Cancer. 2005;41(14): 2120-2131.

5. Kinney WC. A simple and valuable approach for measuring customer satisfaction. Otolaryngol Head Neck Surg. 2005;133(2):169-172.

6. Kola S, Walsh JC. Patients' psychological reactions to colposcopy and LLETZ treatment for cervical intraepithelial neoplasia. Eur J Obstet Gynecol Reprod Biol. 2009;146(1):96-99.

7. Tahseen S, Reid PC. Psychological distress associated with colposcopy: patients' perception. Eur J Obstet Gynecol Reprod Biol. 2008;139(1): 90-94.

8. Walsh JC, Curtis R, Mylotte M. Anxiety levels in women attending a colposcopy clinic: a randomised trial of an educational intervention using video colposcopy. Patient Educ Couns. 2004;55(2): 247-251.

9. Galaal KA, Deane K, Sangal S, Lopes AD. Interventions for reducing anxiety in women undergoing colposcopy. Cochrane Database Syst Rev. 2007;(3):CD006013.

10. Shafi MI, Luesley DM, et al. Randomised trial of immediate versus deferred treatment strategies for the management of minor cervical cytological abnormalities. Br J Obstet Gynaecol. 1997;104(5): 590-594.

11. Oladipo A, Ogden S, Pugh S. Preclinic appointment telephone contact: an effective intervention for colposcopy clinic nonattendance. $J$ Low Genit Tract Dis. 2007;11(1):35-38. 
12. Zissiadis $\mathrm{Y}$, Provis A, Harper E, et al. Patient satisfaction in radiation oncology. Australas Radiol. 2006;50(5):455-462.

13. Wolosin RJ. Patient satisfaction in gastroenterology clinics. Gastroenterol Nurs. 2003;26(5):203-208.

14. Beattie PF, Pinto MB, Nelson MK, Nelson R. Patient satisfaction with outpatient physical therapy: instrument validation. Phys Ther. 2002; 82(6):557-565.
15. Fontanesi J, Alexopoulos C, Goldsman D, et al. Non-punctual patients: planning for variability in appointment arrival times. $J$ Med Pract Manage. 2002;18(1):14-18

\section{Publish your work in this journal}

Patient Related Outcome Measures is an international, peer-reviewed, open access journal focusing on treatment outcomes specifically relevant to patients. All aspects of patient care are addressed within the journal and practitioners from all disciplines are invited to submit their work as well as healthcare researchers and patient support groups. Areas covered will include: Quality of life scores; Patient satisfaction audits; Treatment outcomes that focus on the patient; Research into improving patient outcomes; Hypotheses of interventions to improve outcomes; Short communications that illustrate improved outcomes; Case reports or series that show an improved patient experience; Patient journey descriptions or research.

\footnotetext{
Submit your manuscript here: http://www.dovepress.com/patient-related-outcome-measures-journal
} 